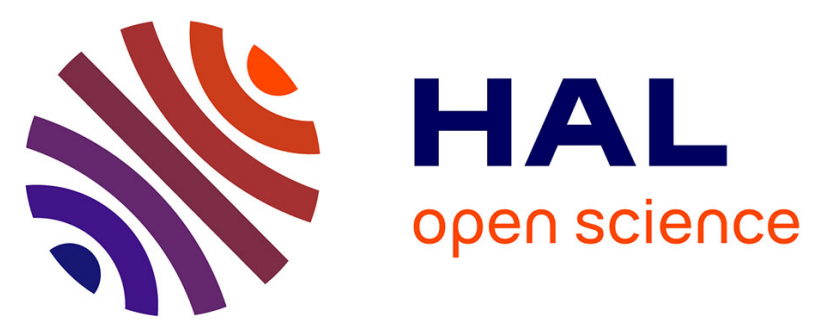

\title{
Brain, physiological and behavioral modulation induced by immune stimulation in honeybees (Apis mellifera): A potential mediator of social immunity?
}

Cédric Alaux, Nele Kemper, Andre Kretzschmar, Yves Le Conte

\section{- To cite this version:}

Cédric Alaux, Nele Kemper, Andre Kretzschmar, Yves Le Conte. Brain, physiological and behavioral modulation induced by immune stimulation in honeybees (Apis mellifera): A potential mediator of social immunity?. Brain, Behavior, and Immunity, 2012, 4 p. 10.1016/j.bbi.2012.04.004 . hal02652017

\section{HAL Id: hal-02652017 \\ https://hal.inrae.fr/hal-02652017}

Submitted on 29 May 2020

HAL is a multi-disciplinary open access archive for the deposit and dissemination of scientific research documents, whether they are published or not. The documents may come from teaching and research institutions in France or abroad, or from public or private research centers.
L'archive ouverte pluridisciplinaire HAL, est destinée au dépôt et à la diffusion de documents scientifiques de niveau recherche, publiés ou non, émanant des établissements d'enseignement et de recherche français ou étrangers, des laboratoires publics ou privés.

\section{(1) (1) $\$$}

Distributed under a Creative Commons Attribution - NonCommercial - NoDerivatives 44.0 


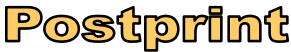

Version définitive du manuscrit publié dans Brain, Behavior and Immunity, DOI : http://dx.doi.org/10.1016/i.bbi.2012.04.004 Available online 19 April 2012 / Final version of the manuscript published in Brain, Behavior and Immunity : Plant Pathology, 2010, DOI : http://dx.doi.org/10.1016/j.bbi.2012.04.004

Brain, physiological and behavioral modulation induced by immune stimulation in honeybees (Apis mellifera): a potential mediator

of social immunity?

Cédric Alaux ${ }^{\mathrm{a}}$, Nele Kemper ${ }^{\mathrm{a}}$, André Kretzschmar ${ }^{\mathrm{b}}$, Yves Le Conte ${ }^{\mathrm{a}}$

${ }^{a}$ INRA, UR406 Abeilles et Environnement, Site Agroparc, 84914 Avignon Cedex 9, France

${ }^{\mathrm{b}}$ INRA, UR546 Biostatistique et Processus Spatiaux, Site Agroparc, 84914 Avignon Cedex 9, France

\section{Corresponding author:}

Cédric Alaux

INRA, UR406 Abeilles et Environnement

Domaine Saint-Paul

84914 Avignon, France

Email : cedric.alaux@avignon.inra.fr

Tel : (33) (0)4 32722618 , Fax : (33) (0)4 32722602

\section{Abstract}

Social removal is often an adaptive response for preventing the entry and spread of parasitic infection between kin members of a group. Social isolation via removal or the switching of social tasks has also been observed in insect societies; however, the underlying mechanisms are unclear. We tested in honeybees the role of the immune system in physiological and behavioral modulation. Forager bees are often located in the outer area of the colony, and thus have reduced contacts with individuals of high importance, who are located in the inner area of the colony (e.g. queen and brood). We thus expected that an immune challenge would induce a forager profile. This was confirmed by measuring brain (foraging and malvolio gene expression), physiological (hypopharyngeal glands size) and behavioral (queen attendance) parameters of nurse/forager profiles after a treatment with an immune-activator (lipopolysaccharides). Our results support the idea that the interplay between the brain and immune system may be an important regulatory factor of social immunity in insects.

Keywords: Social immunity, lipopolysaccharides, honeybees, brain gene expression, queen attendance

\section{Introduction}

Living organisms have developed efficient immune mechanisms to defend themselves against infections. These molecular events involved in the recognition and neutralization of pathogens have been well described, showing some homology between vertebrates and invertebrates (Hoffmann, 2003). However, in parallel with this direct physiological defense, the immune system can interact with the brain leading to 
immune-induced behavioral responses (Hart, 1990). For example, immune-challenged individuals tend to reduce contacts with non-infected conspecifics, which would be adaptive in the sense that it would protect healthy conspecifics from infectious agents (Dantzer, 2004; Hart, 1990).

Behavioral changes induced by this interplay between the immune system and the brain might thus be important in insect societies, since the presence of stored resources and numerous individuals increase both the attractiveness and transmission of pathogens (Schmid-Hempel, 1998). Indeed, social insects can defend themselves through their innate immune system, but they also have developed group-level strategies to prevent disease contamination. This so-called social immunity relies mainly on behavioral responses to infection, like hygienic activity and social isolation (Cremer et al., 2007). For example, studies demonstrated that immune stimulation can lead to modification of social interaction with healthy individuals (Aubert and Richard, 2008; Richard et al., 2008). A more effective response to limit the transmission of pathogens is to isolate oneself from the group (Bos et al., 2011; Heinze and Walter, 2010; Rueppell et al., 2010). A switch in social function could also be observed, with infected individuals abandoning in-nest activity (e.g. queen and brood care) in favor of outdoor and less interactive activity, like foraging activity (Wang and Moeller, 1970). These instances of social removal were general responses of individuals that were dying from the parasite or induced stress. Social isolation has been shown to be triggered by an activation of the immune system in vertebrates (Aubert and Renault, 2008). However, it is not known for social insects whether this social isolation of sick individuals is immune-induced or simply due to the fact that individuals are short-lived (Woyciechowski and Kozlowski, 1998).

To answer this question, we studied the role of the immune system in this behavioral switch by using an immune-activator that does not affect the longevity of individuals. We used the honeybee Apis mellifera and its well-characterized behavioral maturation as a model, and lipopolysaccharides (LPS), molecules found in the outer membrane of Gram-negative bacteria, as a non-pathogenic immune-activator. Honeybee workers undergo a flexible behavioral maturation, spending the first 2-3 weeks of their adult life working in the hive (feeding and taking care of the brood and the queen), and then the rest of their life outside of the hive (foraging for nectar and pollen). We therefore expected immune-stimulated bees to switch behavioral tasks earlier and thus develop a forager profile in order to reduce contact with the rest of the colony (e.g. queen and brood). Three behavioral and physiological parameters of nursing/foraging profiles were measured: queen attendance (i.e. antennating, and licking the queen to spread her pheromones), the expression in the brain of foraging and malvolio, genes that are involved in the development of foraging behavior (Ben-Shahar et al., 2004; Ben-Shahar et al., 2002), and the development of hypopharyngeal glands (HPGs) involved in the secretion of queen and larvae food. By simulating an infection with LPS, we expected to observe a reduction in queen attendance and HPGs size, and an increase in the expression of foraging and malvolio in the brain.

\section{Methods}

\subsection{Bees and experimental set up}

To test the effect of immune reaction on bee physiology and social behavior, we experimentally activated the bee immune system with LPS. The immune response produced by this non-pathogenic can last for days (Korner and Schmid-Hempel, 2004). One-day old bees were paintmarked on the thorax and subjected to the following treatments: sham (handled but not injected), ringer injected and LPS injected (ringer + LPS). Age-matched bees, originating from three hybrid colonies (A. m. ligustica/A. m. mellifera), were obtained by placing honeycombs containing late-stage pupae into an incubator at $34^{\circ} \mathrm{C}$ and collecting bees that emerged within 12 hours.

Comment citer ce document 
For determining the antibacterial activity and mortality induced by the different treatments, all treated bees were housed altogether in the same cages $\left(34^{\circ} \mathrm{C}\right.$ and $70 \%$ relative humidity) and were supplied with water and fed ad libitum with pollen and sugar paste (Apifonda, Südzucker AG Mannheim).

To analyze the effect of immune stimulation on worker/queen interaction, brain gene expression and HPG size, the three treatment groups ( $n$ = 70 bees/treatment group) were housed altogether for 10 days in a one-frame observation hive headed by a mated queen less than one-year old. Each observation hive contained pollen, honey and was provided with water. At day 10, bees were flash frozen in liquid nitrogen to measure brain gene expression and the development of HPGs, which are still developed at this age (Deseyn and Billen, 2005). Each experiment was repeated on three different colonies and treated bees housed together originated from the same colony.

\subsection{LPS treatment}

The honeybee immune system was challenged by injecting into the haemolymph, between the third and fourth tergite, a 4 ul dose of 500 ng/ul LPS (Sigma: Escherichia coli serotype 0128:B12) dissolved in a saline solution commonly used in insect physiology (130 mM NaCl, 6 $\mathrm{mM} \mathrm{KCl,} 4 \mathrm{mM}$ MgCl2, $5 \mathrm{mM} \mathrm{CaCl2,} 160 \mathrm{mM}$ sucrose, 25 mM glucose, $10 \mathrm{mM}$ HEPES, pH 6.7, 500 mOsmol). For controlling the effect of injection and handling, two control groups were created composed of bees injected with 4 ul dose of saline solution alone, and shammanipulated bees submitted to the same manipulations as saline- and LPS-treated bees excluding injections.

\subsection{Antibacterial activity}

To check whether the LPS treatment actually stimulates the bee immune system on the long-term, we measured, 5 days after the different treatments, the antibacterial activity in 9 bees ( 3 of each colony) per treatment. The antibacterial activity was quantified by performing a zone of inhibition assay following the procedure of (Moret and Schmid-Hempel, 2000) and measuring the diameter of the clear zone of inhibition around the haemolymph (Korner and Schmid-Hempel, 2004)

\subsection{Mortality}

For that assay, cages were composed of 15 bees per treatment ( $n=45$ bees/cage), and mortality was followed every day. Two replicates per colony were used. A mortality increase could either be due to a direct effect of LPS treatment or an indirect effect of LPS stimulating the development into foragers, which usually age faster than nurses (Seehuus et al., 2006). We therefore restricted the experiment to 22 days, time at which normal bees start to forage.

\subsection{Queen attendance}

The effect of immune stimulation on queen tending was determined by recording each day the number of bees from each treatment antennating or licking the queen every $30 \mathrm{~min}$. during 8 recording sessions per day. The behavioral experiment was performed from day 2 to 10 after the initial treatment.

\subsection{Brain gene expression}

The effect of immune challenge on foraging and malvolio was determined with quantitative PCRs analysis. Three pools of 3 brains per treatment and colony (total of $n=27$ brains per treatment) were analyzed. The heads were treated with RNAlater Ice (Ambion) following kit instructions and brains were dissected on ice. Brains were homogenized in Trizol (Invitrogen) and RNA extraction was carried out as indicated in the Qiagen RNeasy kit (Qiagen) with on column DNase I treatment (Qiagen). For cDNA synthesis, 200 ng of RNA per sample 
was reverse-transcribed using the SuperScript III kit (Invitrogen). Analyses were carried out with a StepOnePlus Real-Time PCR Systems (Applied Biosystems) and the SYBR green detection method (Applied Biosystems) including the ROX passive reference dye. Ct values of selected genes were normalized to the housekeeping gene actin and relative to a control sample using 2-(delta-delta Ct). Primer sequences (5' to 3') were: foraging forward: AATATAACTTCCGGTGCAACGTATT, reverse : CGTTTGGATCACGGAAGAAAG (Ben-Shahar et al., 2002) ; malvolio forward: CCTTGGTATAAAGATTATGACAGGAATATG, reverse: CAAGAGCACTGTGAAGATACAAGTTATG (Ben-Shahar et al., 2004); actin forward: TGCCAACACTGTCCTTTCTG, reverse: AGAATTGACCCACCAATCCA.

\subsection{Development of HPGs}

Glands from 9 bees per treatment and colony were dissected on ice and deposited in $100 \mu$ l of physiological serum ( $0.9 \% \mathrm{NaCl}$ ). Then, the gland development was assessed by measuring the maximum diameter of 15 randomly chosen ovoid acini per gland ( $n=30$ acini per bees) with a micrometer under a stereomicroscope (Crailsheim and Stolberg, 1989).

\subsection{Statistics}

Two-way ANOVAs followed by Bonferroni post-hoc tests were performed for testing the effect of treatment and colony on antibacterial activity, mortality, the development of brain gene expression and HPGs. For the queen tending behavior, the treatment, age and colony effects were measured using a multinomial model at the individual level, where the total number $n$ of bees tending the queen, for any observation $\mathrm{X}$, results from a multinomial distribution with probabilities $p_{1}, p_{2}$ and $p_{3}$ to belong to Sham, Ringer and LPS treatment, respectively (mlogit package $0.2-2$, ULCA, $\mathrm{R}$ software): $\mathrm{X}=\operatorname{multinomial}\left(n,\left(p_{1}, p_{2}, p_{3}\right)\right)$ and $p_{1}+p_{2}+p_{3}=1$

\section{Results}

\subsection{Antibacterial activity}

LPS treatment induced a significant increase in antibacterial activity (zones of inhibition (mean \pm SE): sham-manipulated: $0.98 \pm 0.25$ mm, ringer-injected: $2.59 \pm 0.49$, LPS: $4.32 \pm 0.51 \mathrm{~mm} ; F_{2,24}=16.59, \mathrm{P}<0.001$; post-hoc tests: sham $v s$ LPS: $p<0.0001$, Ringer $v s$ LPS: $p=$ 0.023). The ringer injection also stimulated the antibacterial activity (sham vs Ringer: $p=0.038$ ). No colony effect and treatment by colony interaction was found $\left(F_{2,24}=1.52, p=0.25\right.$ and $\left.F_{4,24}=1.48, p=0.25\right)$.

\subsection{Mortality}

The immune challenge did not affect the longevity of bees over 22 days (number of dead bees: sham-manipulated: $2.5 \pm 0.62$, Ringerinjected: $3 \pm 0.89$, LPS: $\left.3.66 \pm 0.56 ; F_{2,17}=0.63, p=0.55\right)$. No colony effect and treatment by colony interaction was found $\left(F_{2,17}=1.69, p=\right.$ 0.24 and $\left.F_{4,17}=0.32, p=0.86\right)$.

\subsection{Queen attendance}

The Ringer and LPS treatments decreased the probabilities of queen tending as compared to Sham treatment $(t=-4.19, p<0.001$ and $t=-$ 3.25, $p<0.005$, respectively; Fig. 1). However, there was no difference between Ringer and LPS treatments $(t=0.34, p=0.34)$. We did not find any colony effect for each treatment ( $p>0.05$ for each colony comparison), except in colony 3 where the percentage of LPS-treated bees was lower than in colony $1(t=-2.09, p=0.037)$. Finally, no effect of age was found for the Sham treatment $(p>0.05$ for each age comparison) but Ringer-treated bees tended more the queen on days 4, 5 and 6 than on day $2(t=2.2, p=0.028 ; t=2.72, p<0.01 ; t=2.68, p$ $<0.01$, respectively) and LPS-treated bees were also more likely to tend the queen on day 6 than on day $2(t=2.24, p=0.025)$.

Comment citer ce document 


\title{
3.4. Brain gene expression
}

LPS treatment induced the upregulation in the bee brain of foraging and malvolio expression (foraging: $F_{2,18}=7.18, p<0.01$ and malvolio: $F_{2,18}=15.19, p<0.001$; Fig. $\left.2 \mathrm{~A}\right)$. We did not find any significant effect of the colony $\left(F_{2,18}=0.1, p=0.91\right.$ and $\left.F_{2,18}=0.34, p=0.71\right)$ or treatment by colony interaction $\left(F_{2,18}=0.82, p=0.53\right.$ and $\left.F_{2,18}=0.86, p=0.32\right)$ on the expression of both genes.

\subsection{Development of HPGs}

Immune stimulation significantly reduced the development of HPGs $\left(F_{2,67}=7.03, p<0.001\right.$; Fig. 2B). There was no significant effect of colony $\left(F_{2,67}=2.38, p=0.09\right)$ or any treatment by colony interaction $\left(F_{4,67}=1.14, p=0.34\right)$ on gland size.

\section{Discussion} \\ With this study, we showed that non-pathogenic immune stimulation can modify the physiology and social behavior of honeybees. These \\ results suggest that the immune system not only help individuals to defend themselves against infection but can also reshape their role in the \\ group.
}

When compared to bees injected with ringer solution, LPS-injected bees exhibited a forager-like profile with a low HPG development but a higher brain gene expression of foraging and malvolio, demonstrating that the observed physiological changes were not due to detrimental effects of injection but to LPS. Regarding queen attendance, we did not observe the same pattern. However, the number of bees performing queen attendance, despite being lower than in the sham treatment, did not differ between the ringer and LPS treatments, indicating that injection also affected this social behavior. This, as well as the change in malvolio expression induced by ringer injection, might be explained by the fact that ringer-treated bees also exhibited an increase of antibacterial activity likely due to wounding and injection, as previously found by (Korner and Schmid-Hempel, 2004; Richard et al., 2008).

Similar to the social isolation of sick individuals exhibited by mammals (Dantzer, 2004; Hart, 1990), the forager-like profile induced by the immune stimulation might represent an adaptive response to protect the queen, who is usually the unique reproductive individual of the colony, the brood and the young nurse bees from a potential infection. Indeed, moving to the outer area of the colony implies a reduction of contacts with those individuals of high importance (Cremer et al., 2007). The queen tending was significantly reduced but still exhibited by immune-challenged bees, which might have limited effect on the queen protection. However, as compared to the one frame hive of few bees, it might be easier for sick bees to move to the outer area and/or "avoid" the queen attraction in a real colony composed of thousands of individuals. In addition, it is possible that true infection induces a more drastic behavioral change. Social removal has already been observed in ants (Heinze and Walter, 2010) and bees (Rueppell et al., 2010), but this phenomenon could potentially due to the fact that individuals were dying (Woyciechowski and Kozlowski, 1998). With this study, we showed that the activation of the immune system, excluding any lifespan shortening, can initiate those changes in bees. Since parasitism or immune activation can modify the chemical profile of bees (Richard et al., 2008; Salvy et al., 2001), this social-removal to protect the colony might also be prompted by conspecifics, who detected and modified their interactions with sick bees (Richard et al., 2008). However, similarly to Heinze and Walter (2010) and Rueppell et al. (2010), we did not see any signs of antagonist interactions. 
Deficiencies in associative learning have been found in honeybees and bumblebees days after an immune challenge (Mallon et al., 2003; Riddell and Mallon, 2006). Our results confirm that immune-induced changes, likely due to the launch of molecular cascades and/or to the persistent antibacterial activity (Korner and Schmid-Hempel, 2004), can be chronic in insects but the underlying mechanisms are still misunderstood. We showed that immune activation can lead to a change in phenotype, but the mechanisms linking the immune to the social role changes are still unknown. In vertebrates, this close relationship between the immune, endocrine and nervous system is notably mediated by cytokines (Aubert and Renault, 2008). Cytokine-like factors have been identified in insects (Gillespie et al., 1997) but whether they are involved in immune regulation of behavior remains to be studied. Juvenile hormone can act as an immune-regulator in insects (Flatt et al., 2008; Tian et al., 2010), and more specifically in bees, via the action of vitellogenin (Amdam et al., 2004), which is interesting since juvenile hormone also plays an important role in regulating behavioral tasks in honeybees (Amdam and Page, 2010). Juvenile hormone might thus be here a key mediator of the interaction between the nervous and immune system, but this remains to be investigated.

Social immunity depends on behavioral and organizational adaptation of the group to prevent the outbreak and establishment of parasitic infection. Here, we have provided experimental evidence for the role of the immune system in the initiation of this phenomenon. Social immunity might therefore represent an interesting behavioral paradigm to study the evolutionary processes of psychoneuroimmunology, analyzing the interface between behavior, brain and immunity (Dantzer, 2004).

\section{Acknowledgments}

We thank J. Brillard, M. Charreton and D. Crauser for help with the experiments and C. McDonnell for comments that improve the manuscript. This work was funded by an INRA grant to C. Alaux.

\section{References}

Amdam, G.V., Page, R.E., 2010. The developmental genetics and physiology of honeybee societies. Anim. Behav. 79, 973-980.

Amdam, G.V., Simões, Z.L.P., Hagen, A., Norberg, K., Schrøder, K., Mikkelsen, Ø., Kirkwood, T.B.L., Omholt, S.W., 2004. Hormonal control of the yolk precursor vitellogenin regulates immune function and longevity in honeybees. Exp. Gerontol. 39, 767-773.

Aubert, A., Renault, J., 2008. Cytokines and Immune-Related Behaviors. In: Phelps, C., Korneva, K. (Eds.), NeuroImmune Biology. Elsevier Science, pp. 529-547.

Aubert, A., Richard, F.J., 2008. Social management of LPS-induced inflammation in Formica polyctena ants. Brain Behav. Immun. 22, 833837.

Ben-Shahar, Y., Dudek, N.L., Robinson, G.E., 2004. Phenotypic deconstruction reveals involvement of manganese transporter malvolio in honey bee division of labor. J. Exp. Biol. 207, 3281-3288.

Ben-Shahar, Y., Robichon, A., Sokolowski, M.B., Robinson, G.E., 2002. Influence of gene action across different time scales on behavior. Science 296, 741-744

Bos, N., Lefevre, T., Jensen, A.B., D'Ettorre, P., 2011. Sick ants become unsociable. J Evol Biol.

Crailsheim, K., Stolberg, E., 1989. Influence of diet, age and colony condition upon intestinal proteolytic activity and size of the hypopharyngeal glands in the honeybee (Apis mellifera L). J. Insect. Physiol. 35, 595-602.

Cremer, S., Armitage, S.A., Schmid-Hempel, P., 2007. Social immunity. Curr. Biol. 17, R693-702.

Dantzer, R., 2004. Innate immunity at the forefront of psychoneuroimmunology. Brain Behav. Immun. 18, 1-6. 
Deseyn, J., Billen, J., 2005. Age-dependent morphology and ultrastructure of the hypopharyngeal gland of Apis mellifera workers (Hymenoptera, Apidae). Apidologie 36, 49-57.

Flatt, T., Heyland, A., Rus, F., Porpiglia, E., Sherlock, C., Yamamoto, R., Garbuzov, A., Palli, S.R., Tatar, M., Silverman, N., 2008. Hormonal regulation of the humoral innate immune response in Drosophila melanogaster. J. Exp. Biol. 211, $2712-2724$.

Gillespie, J.P., Kanost, M.R., Trenczek, T., 1997. Biological mediators of insect immunity. Ann. Rev. Entomol. 42, $611-643$.

Hart, B.L., 1990. Behavioral Adaptations to Pathogens and Parasites - 5 Strategies. Neurosci. Biobehav. R 14, $273-294$.

Heinze, J., Walter, B., 2010. Moribund ants leave their nests to die in social isolation. Curr. Biol. 20, 249-252.

Hoffmann, J.A., 2003. The immune response of Drosophila. Nature 426, 33-38.

Korner, P., Schmid-Hempel, P., 2004. In vivo dynamics of an immune response in the bumble bee Bombus terrestris. J. Invertebr. Pathol. 87, 59-66.

Mallon, E.B., Brockmann, A., Schmid-Hempel, P., 2003. Immune function inhibits memory formation in the honeybee Apis mellifera. Proc. Roy. Soc. B 270, 2471-2473.

mlogit package 0.2-2, R Data Analysis Examples. UCLA, Academic Technology Services, Statistical Consulting Group. http://www.ats.ucla.edu/stat/r/dae/

Moret, Y., Schmid-Hempel, P., 2000. Survival for immunity: the price of immune system activation for bumblebee workers. Science 290, 1166-1168.

Richard, F.-J., Aubert, A., Grozinger, C.M., 2008. Modulation of social interactions by immune stimulation in honey bee, Apis mellifera, workers. BMC Biology 6, 50 .

Riddell, C.E., Mallon, E.B., 2006. Insect psychoneuroimmunology: immune response reduces learning in protein starved bumblebees (Bombus terrestris). Brain Behav. Immun. 20, 135-138.

Rueppell, O., Hayworth, M.K., Ross, N.P., 2010. Altruistic self-removal of health-compromised honey bee workers from their hive. J. Evolution. Biol. 23, 1538-1546.

Salvy, M., Martin, C., Bagneres, A.G., Provost, E., Roux, M., Le Conte, Y., Clement, J.L., 2001. Modifications of the cuticular hydrocarbon profile of Apis mellifera worker bees in the presence of the ectoparasitic mite Varroa jacobsoni in brood cells. Parasitology 122, $145-159$.

Schmid-Hempel, P., 1998. Parasites in Social Insects. Princeton University Press, Princeton, NJ.

Seehuus, S.C., Norberg, K., Gimsa, U., Krekling, T., Amdam, G.V., 2006. Reproductive protein protects functionally sterile honey bee workers from oxidative stress. Proc. Natl. Acad. Sci. USA 103, 962-967.

Tian, L., Guo, E., Diao, Y., Zhou, S., Peng, Q., Cao, Y., Ling, E., Li, S., 2010. Genome-wide regulation of innate immunity by juvenile hormone and 20-hydroxyecdysone in the Bombyx fat body. BMC Genomics 11, 549.

Wang, D.I., Moeller, F.E., 1970. The division of labor and queen attendance behavior of Nosema infected worker honeybees. J. Econ. Entomol. 63, 1539-1541.

Woyciechowski, M., Kozlowski, J., 1998. Division of labor by division of risk according to worker life expectancy in the honey bee (Apis mellifera L.). Apidologie 29, 191-205 


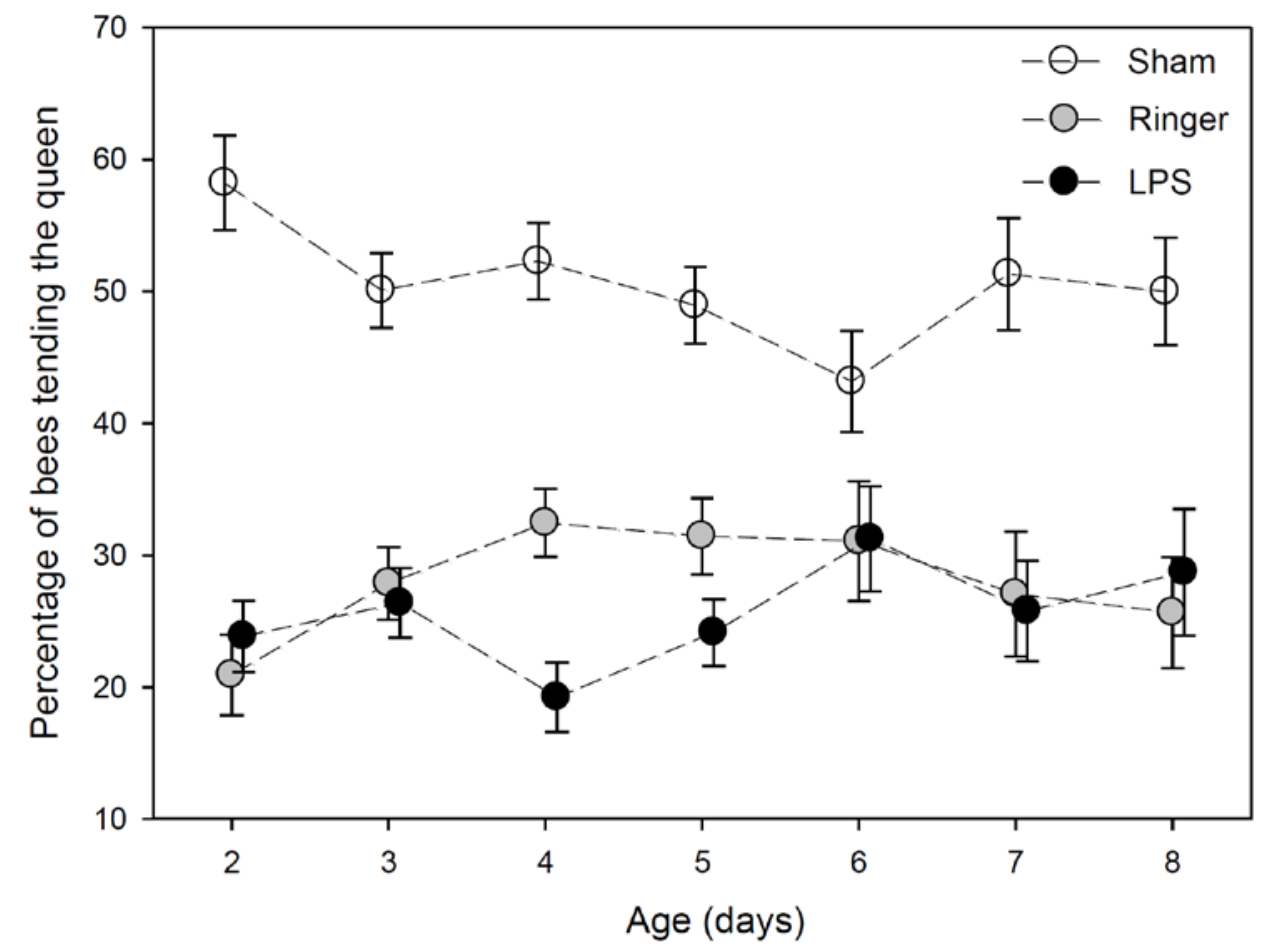

Figure 1. Behavioral response to immune challenge. The mean percentages of treated bees tending the queen is shown ( $n=3$ colonies). A circle of 4 to 13 bees attended the queen. Error bars denote S.E.

A

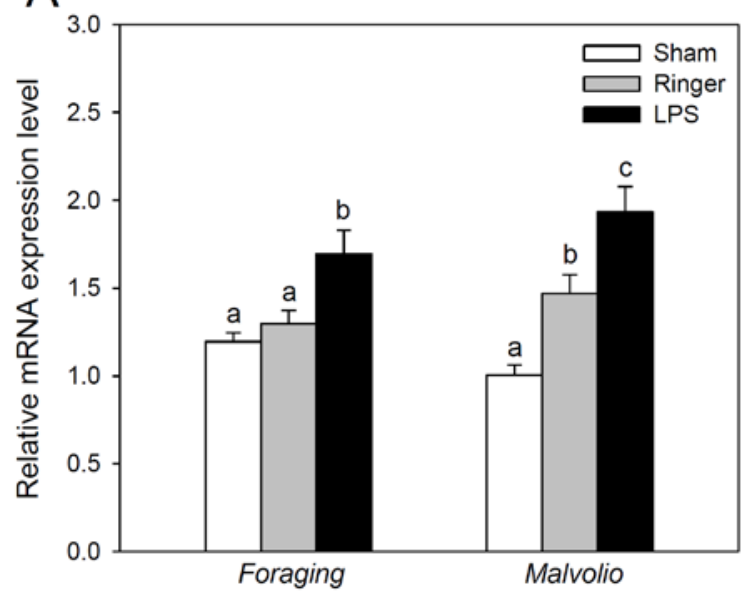

B



Figure 2. Brain and physiological responses to immune challenge. (A) The brain gene expression of foraging and malvolio was higher following the LPS treatment as compared to ringer-injected ( $p=0.031$ and $p<0.01)$ and sham-operated bees $(p=0.039$ and $p<0.001)$. No difference in the expression level of foraging was found between ringer-treated and sham-operated bees $(p=0.47)$, but malvolio was lower expressed in the latter bees $(p=0.038) . n=3$ pools of 3 brains/treatment and colony. (B) The HPGs development was significantly reduced by LPS treatment in comparison to ringer-treated $(p=0.021)$ and sham-operated bees $(p<0.005)$. No difference was found between ringertreated and sham-operated bees $(p=0.14) . n=9$ bees/treatment and colony. Different letters indicate significant differences and error bars denote S.E. 